\title{
Comparison of cell-wall polysaccharides from Nectria cinnabarina with those from the group of Nectria with Sesquicillium anamorphs
}

\author{
Oussama Ahrazem, ${ }^{1}$ Alicia Prieto, ${ }^{1}$ Begoña Gómez-Miranda, ${ }^{1}$ \\ Manuel Bernabé ${ }^{2}$ and J. Antonio Leal ${ }^{1}$
}

1 Centro de Investigaciones Biológicas, CSIC, Velázquez 144, 28006-Madrid, Spain

2 Instituto de Química Orgánica, Departamento de Química Orgánica Biológica, CSIC, Juan de la Cierva 3, 28006-Madrid, Spain

\author{
Author for correspondence: Antonio Leal. Tel: +34 915611800 ext. 4437. Fax: +34915627518. \\ e-mail: aleal@cib.csic.es
}

\begin{abstract}
Alkali-extractable and water-soluble polysaccharides were purified from cell walls of five species of Sesquicillium or its teleomorphs, Nectria lasiacidis and Nectria impariphialis, and from Nectria cinnabarina, the type species of Nectria, a heterogeneous genus that belongs to the Hypocreales. Methylation and NMR analyses for determination of linkage types and structure were performed and indicated differences between the polysaccharides purified during the present study and those isolated from other nectrioid fungi, namely the presence of 5 -O-substituted galactofuranose $(\rightarrow 5)$-Galf-(1 $\rightarrow)$ in the main chain together with 2,6-di-O-substituted galactofuranose $(\rightarrow 2,6)$-Galf-(1 $\rightarrow)$ residues in Sesquicillium buxi and Sesquicillium pseudosetosum. The polysaccharide from $N$. impariphialis was similar to those obtained from the above species, although an additional residue of 6-0-substituted glucopyranose $(\rightarrow 6)$-GIcp$(1 \rightarrow)$, was detected in some side chains. In $N$. lasiacidis and Sesquicillium candelabrum the polysaccharide contained an additional branching point of 5,6-di-O-substituted galactofuranose $(\rightarrow 5,6)$-Galf- $(1 \rightarrow)$ linked to terminal $N$ acetylglucosamine GIcNAc- $(1 \rightarrow)$. These chains were linked to a small mannan core. All these polysaccharides showed major differences to the polysaccharide of $N$. cinnabarina, which was formed by a main chain of $(1 \rightarrow 6)$ - $\beta$-linked galactofuranose units almost fully branched at positions 2-0 by either single residues of glucopyranose or acidic chains containing glucuronic acid and mannose.
\end{abstract}

Keywords: complex galactans, Hypocreales, chemotaxonomy

\section{INTRODUCTION}

The genus Sesquicillium Gams was created by the transfer (Gams, 1968) of Fusidium buxi Schmidt in Link and Verticillium candelabrum Bonorden. It is characterized by the presence of verticillate conidiophores, whose ultimate branches consist of terminal tapering phialides and subterminal cells with a lateral sporiferous neck. Five new species of Nectria with Sesquicillium anamorphs were described by Samuels (1989). He found that the anamorphs of Nectria sesquicilli and Nectria lasiacidis were indistinguishable from Sesquicillium buxi and he erected three species of Sesquicillium with the anamorphs of the other species of Nectria:

Abbreviation: TMS, trimethylsilyl.
Sesquicillium asymmetricum (Nectria sesquiphialis), Sesquicillium impariphiale (Nectria impariphialis) and Sesquicillium pseudosetosum (Nectria parviphialis). These species of Nectria form a homogeneous group characterized by superficial, non-stromatic, smooth globose, non-papillate, orange perithecia. The known species of Sesquicillium and their Nectria teleomorphs were keyed by Samuels (1989). Recently, Rossman et al. (1999) erected a new genus, Bionectria, in which the species of Nectria with anamorphs in Sesquicillium are included.

The type species of the genus Nectria is Nectria cinnabarina (Tode: Fr.) Fr. The characteristics of species related to $N$. cinnabarina, included in the $N$. cinnabarina group, were discussed by Rossman (1989). In a later work this author expressed the opinion that the genus Nectria should be restricted to the N. cinnabarina group 
Table 1. Sugar composition (\%) of fraction F1S-Il of Sesquicillium species, $N$. impariphialis, $N$. cinnabarina and $N$. lasiacidis

Glc, glucose; Gal, galactose; Man, mannose; GlcA, glucuronic acid; GlcNAc, N-acetylglucosamine.

\begin{tabular}{|c|c|c|c|c|c|c|}
\hline Micro-organism & Glc & Gal & Man & GlcA & GlcNAc & $\begin{array}{c}\text { Recovery } \\
(\%)\end{array}$ \\
\hline N. cinnabarina CBS 279.48 & $16 \cdot 8 \pm 1 \cdot 2$ & $25 \cdot 9 \pm 0 \cdot 8$ & $7 \cdot 3 \pm 0 \cdot 6$ & $7 \cdot 5 \pm 0 \cdot 5$ & - & $57 \cdot 5$ \\
\hline N. cinnabarina CBS 278.48 & $23 \cdot 2 \pm 1 \cdot 5$ & $33 \cdot 7 \pm 1 \cdot 1$ & $12 \cdot 0 \pm 0 \cdot 8$ & $8 \cdot 9 \pm 1 \cdot 0$ & - & $77 \cdot 8$ \\
\hline N. cinnabarina CBS 255.47 & $16 \cdot 5 \pm 2 \cdot 1$ & $23 \cdot 6 \pm 1 \cdot 6$ & $11 \cdot 3 \pm 0 \cdot 6$ & $7 \cdot 8 \pm 0 \cdot 9$ & - & $59 \cdot 4$ \\
\hline S. buxi CBS 288.62 & $9 \cdot 7 \pm 1 \cdot 9$ & $52 \cdot 2 \pm 1 \cdot 4$ & $7 \cdot 2 \pm 0 \cdot 9$ & $3 \cdot 5 \pm 0 \cdot 3$ & - & $72 \cdot 6$ \\
\hline S. pseudosetosum CBS 662.83 & $10 \cdot 3 \pm 0 \cdot 7$ & $45 \cdot 1 \pm 1 \cdot 3$ & $7 \cdot 7 \pm 0 \cdot 5$ & $2 \cdot 5 \pm 0 \cdot 4$ & - & $65 \cdot 6$ \\
\hline S. candelabrum CBS 190.38 & $7 \cdot 5 \pm 1 \cdot 4$ & $48 \cdot 5 \pm 1 \cdot 1$ & $6 \cdot 5 \pm 0 \cdot 4$ & $1 \cdot 5 \pm 0 \cdot 2$ & $7 \cdot 0 \pm 1 \cdot 2$ & $71 \cdot 0$ \\
\hline S. candelabrum CBS 205.69 & $10 \cdot 5 \pm 1 \cdot 3$ & $45 \cdot 4 \pm 1 \cdot 7$ & $7 \cdot 6 \pm 0 \cdot 6$ & $1 \cdot 0 \pm 0 \cdot 3$ & $7 \cdot 5 \pm 1 \cdot 1$ & $73 \cdot 0$ \\
\hline S. candelabrum CBS 204.69 & $12 \cdot 6 \pm 2 \cdot 9$ & $30 \cdot 7 \pm 1 \cdot 3$ & $6 \cdot 5 \pm 0.6$ & $1 \cdot 8 \pm 0 \cdot 3$ & $7 \cdot 3 \pm 1 \cdot 4$ & $59 \cdot 6$ \\
\hline N. lasiacidis CBS 179.88 & $16 \cdot 1 \pm 2 \cdot 5$ & $27 \cdot 8 \pm 0 \cdot 9$ & $6 \cdot 1 \pm 0 \cdot 5$ & $3 \cdot 0 \pm 0 \cdot 8$ & $7 \cdot 8 \pm 1 \cdot 6$ & $60 \cdot 8$ \\
\hline N. impariphialis CBS 178.88 & $35 \cdot 7 \pm 1 \cdot 1$ & $38 \cdot 4 \pm 1 \cdot 4$ & $7 \cdot 0 \pm 0 \cdot 6$ & $4 \cdot 0 \pm 0 \cdot 5$ & - & $85 \cdot 1$ \\
\hline
\end{tabular}

(Rossman, 1993). The large number of species included in the genus Nectria made it necessary to divide them into groups according to morphological features (Booth, 1959). Other workers have added new species, elucidated additional characters and substantiated the groups (Samuels \& Rossman, 1979; Seifert, 1985; Samuels \& Seifert, 1987; Rossman, 1989, 1993).

Various species of Sesquicillium have been misidentified because of the morphological similarities with other genera. As an example, some strains of $S$. candelabrum were named Gliocladium penicilloides and Verticillium candelabrum prior to their final inclusion in Sesquicillium (Domsch et al., 1980). Morphological characters are sometimes insufficient to delineate unequivocally fungal genera; therefore, chemical and biochemical characters and, most recently, rDNA sequencing are increasingly used in fungal systematics.

Monosaccharide composition of the cell wall has been used for yeast and fungal taxonomy, systematics and phylogeny (Weijman \& Golubev, 1987; Prillinger et al., 1990, 1991, 1993; Messner et al., 1994). Bartnicki-García (1968) proposed the use of dual combinations of major polysaccharides of the cell wall to classify fungal species and divided the whole spectrum of fungi into eight categories. As Pfyffer (1998) stated: 'cell wall polysaccharides appear to be extremely conservative and therefore may be considered reliable markers for fungal taxonomy.' The alkali-extractable and water-soluble polysaccharides from the cell walls have been proposed as taxonomic characters for various fungal genera (Leal \& Bernabé, 1998). Among the Hypocreales, some polysaccharides have been proposed as markers for Calonectria and its anamorph, Cylindrocladium (Ahrazem et al., 1997), and for Gibberella and Fusarium (Ahrazem et al., 2000). As stated above, the perfect state of Sesquicillium species belongs to Nectria. This genus is heterogeneous, since it comprises the teleomorphic states of 21 anamorphic genera (Samuels \& Seifert, 1987). The concept of Nectria has changed according to the weight given to the morphological and biological characteristics of both the teleomorph and the anamorph by different authors (Rossman, 1993; Rossman et al., 1999).

In this work we characterize the alkali-extractable, water-soluble cell-wall polysaccharides from isolates of N. cinnabarina, and of Sesquicillium and Nectria with Sesquicillium anamorphs, in an attempt to find out if the morphological differences which allowed the arrangement of Nectria with Sesquicillium anamorphs in a group are reflected in the composition of the cell-wall polysaccharides.

\section{METHODS}

Micro-organisms and culture media. The strains of Nectria and Sesquicillium listed in Table 1 were maintained on slants of Bacto potato dextrose agar supplemented with $1 \mathrm{~g} \mathrm{l}^{-1}$ yeast extract (Difco). N. lasiacidis and N. impariphialis are teleomorphs of S. buxi (Gams, 1968) and S. impariphiale (Samuels, 1989), respectively. The culture medium and growth conditions were as previously described (Gómez-Miranda et al., 1988).

Wall material preparation and fractionation. Wall material was obtained as reported elsewhere (Prieto et al., 1988). Cellwall material $(8 \mathrm{~g})$ was repeatedly extracted with $1 \mathrm{M} \mathrm{NaOH}$ $(300 \mathrm{ml})$ at $20^{\circ} \mathrm{C}$. After centrifugation, the supernatants were combined and absolute ethanol $(\mathrm{v} / \mathrm{v})$ was added. The precipitate was collected by centrifugation, dialysed against running tap water and then freeze-dried (F1). This polysaccharidic material $(500 \mathrm{mg}$ ) was suspended in distilled water $(10 \mathrm{ml})$, stirred at room temperature for $2 \mathrm{~h}$ and centrifuged. The precipitate was extracted again with distilled water and the supernatant solutions were combined and freeze-dried (F1S).

Isolation of polysaccharides from F1S. A $100 \mathrm{mg}$ aliquot of fraction F1S was dissolved in $1.5 \mathrm{ml}$ distilled water and centrifuged at $13000 \mathrm{~g}$ for $15 \mathrm{~min}$ to eliminate insolubles. The supernatant was added to a column $(90 \times 2.6 \mathrm{~cm})$ of Sepharose CL-6B and eluted with distilled water with a flow of $22 \mathrm{ml} \mathrm{h}^{-1}$. Fractions were collected and monitored for carbohydrate by 

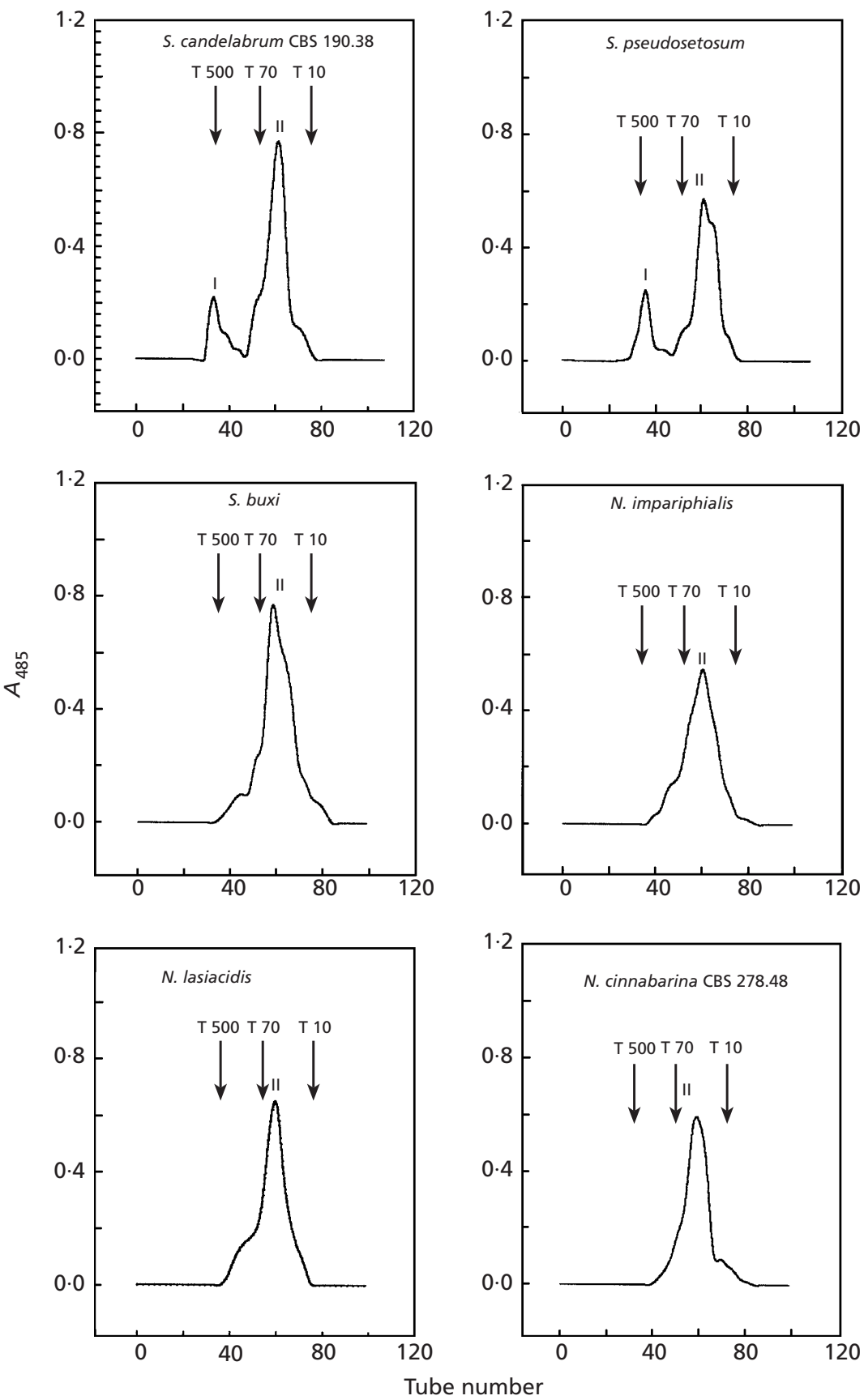

Fig. 1. Column chromatography of F1S from Sesquicillium species, $N$. lasiacidis, $N$. cinnabarina CBS 278.48 and $N$. impariphialis on Sepharose CL-6B. The arrows indicate the elution of the different dextrans (500, 70 and $10 \mathrm{kDa}$ ) used as standards for calibration. the phenol-sulfuric acid method (Dubois et al., 1956). The fractions which gave a positive test for carbohydrates were combined in batches of six successive fractions, concentrated to a small volume and freeze-dried. The column was previously calibrated with a mixture of standards: T500, T70 and T10 dextrans (Pharmacia).

Chemical analysis. Neutral sugars were analysed by methanolysis followed by hydrolysis with $3 \mathrm{M}$ trifluoroacetic acid (1 h at $\left.121^{\circ} \mathrm{C}\right)$. Neutral sugars were converted into their corresponding alditol acetates (Laine et al., 1972) and identified and quantified by GLC as described previously (GómezMiranda et al., 1981). Uronic acid content was measured by the carbazole reaction (Bitter \& Muir, 1962) and the acidic monosaccharides identified on the hydrolysates as their trimethylsilyl (TMS)-derivatives by GLC-MS. The carboxylic groups of the uronic acids in the polysaccharide were reduced with sodium borodeuteride $\left(\mathrm{NaBD}_{4}\right)$ according to the method of Taylor \& Conrad (1972). The complete reduction was checked by IR spectroscopy. IR spectra were obtained by the $\mathrm{KBr}$ technique (Price, 1972) on a Perkin-Elmer 1420 infrared spectrophotometer. Aminosugar content was determined after hydrolysis of the polysaccharides $\left(6 \mathrm{M} \mathrm{HCl}, 4 \mathrm{~h}, 100^{\circ} \mathrm{C}\right)$ according to the method of Chen \& Johnson (1983) and glucosamine was identified by HPLC in an amino acid analyser Biochrom 20 (Pharmacia) using commercial standards.

Absolute configuration of the monosaccharides. The monosaccharides released in the hydrolysates were derivatized according to the method of Gerwig et al. (1979) and their 
Table 2. Methylation and reductive cleavage analyses (\%) from F1S-Il of several species of Sesquicillium, N. impariphialis, N. cinnabarina and N. lasiacidis

N. cin, N. cinnabarina; N. imp, N. impariphialis; N. las, N. lasiacidis; S. bux, S. buxi; S. can, S. candelabrum; S. pse, S. pseudosetosum.

\begin{tabular}{|c|c|c|c|c|c|c|}
\hline Linkage type & N. $\operatorname{cin}^{*}$ & S. bux & S. pse & S. can $\dagger$ & N. las & N. imp \\
\hline GlcNAc- $(1 \rightarrow \ddagger$ & - & - & - & $3 \cdot 0$ & $2 \cdot 7$ & - \\
\hline Glcp- $(1 \rightarrow$ & $29 \cdot 1$ & $20 \cdot 9$ & $29 \cdot 8$ & $25 \cdot 4$ & $28 \cdot 7$ & $13 \cdot 6$ \\
\hline GlcpA- $(1 \rightarrow \mathbb{S}$ & - & $3 \cdot 1$ & $1 \cdot 8$ & $1 \cdot 2$ & $2 \cdot 5$ & $2 \cdot 5$ \\
\hline $\operatorname{Man} p-(1 \rightarrow$ & $4 \cdot 9$ & - & - & - & - & - \\
\hline$\rightarrow 5)$-Galf-(1 $\rightarrow$ & $2 \cdot 0$ & $33 \cdot 5$ & $35 \cdot 1$ & $34 \cdot 5$ & $24 \cdot 4$ & $39 \cdot 5$ \\
\hline$\rightarrow 6)-\operatorname{Man} p-(1 \rightarrow$ & $4 \cdot 0$ & $2 \cdot 0$ & $1 \cdot 5$ & $2 \cdot 5$ & $2 \cdot 3$ & - \\
\hline$\rightarrow 6)-$ Glc $p-(1 \rightarrow$ & - & - & - & - & - & $17 \cdot 9$ \\
\hline$\rightarrow 4)$-GlcpA-(1 $\rightarrow \|$ & $5 \cdot 0$ & - & - & - & - & - \\
\hline$\rightarrow 6)$-Galf-(1 $\rightarrow$ & $8 \cdot 6$ & $2 \cdot 5$ & $3 \cdot 0$ & $3 \cdot 5$ & $5 \cdot 0$ & $2 \cdot 3$ \\
\hline$\rightarrow 2,6)-\mathrm{Man} p-(1 \rightarrow$ & $3 \cdot 0$ & - & $0 \cdot 6$ & - & - & - \\
\hline$\rightarrow 4,6)-\operatorname{Man} p-(1 \rightarrow$ & - & $1 \cdot 1$ & - & $2 \cdot 0$ & - & - \\
\hline$\rightarrow 5,6)-$ Gal $f-(1 \rightarrow$ & - & - & - & $6 \cdot 0$ & $7 \cdot 5$ & - \\
\hline$\rightarrow 2,6)-G a l f-(1 \rightarrow$ & $33 \cdot 1$ & $22 \cdot 5$ & $27 \cdot 9$ & $20 \cdot 0$ & $20 \cdot 5$ & $15 \cdot 5$ \\
\hline
\end{tabular}

* Results for isolate CBS 278.48. Similar residues and proportions were found in the other isolates of N. cinnabarina.

† Results for isolate CBS 190.38. Similar residues and proportions were found in the other isolates of S. candelabrum.

$\ddagger$ Detected in the analysis of the native polysaccharide.

SDetected as 1,5-diacetyl-2,3,4,6-Me $-\mathrm{Me}_{4}$-Glc with $2 \mathrm{D}$ atoms in C6 (reduced carboxyl).

|| Detected as 1,4,5-diacetyl-2,3,6- $\mathrm{Me}_{3}$-Glc with $2 \mathrm{D}$ atoms in C6 (reduced carboxyl).

absolute configuration determined by GLC-MS of the tetra-OTMS-(+)-2-butylglycosides obtained.

Linkage analyses. The reduced polysaccharides $(1-5 \mathrm{mg})$ were methylated according to the method of Ciucanu \& Kerek (1984). The polysaccharides that contained aminosugars were also methylated by the same protocol without reducing the carboxylic group. The methylated material was extracted with chloroform/methanol $(1: 1, \mathrm{v} / \mathrm{v})$, dialysed sequentially against water and $50 \%$ ethanol, and evaporated. Methylated fractions, which showed negligible IR absorption for hydroxyl groups, were hydrolysed with $3 \mathrm{M}$ trifluoroacetic acid $\left(121^{\circ} \mathrm{C}\right.$, $1 \mathrm{~h})$, and the products were reduced with $\mathrm{NaBD}_{4}$, then acetylated and subjected to GLC-MS, using a SPB-1 column (30 $\mathrm{m} \times 0.22 \mathrm{~mm}$ i.d. $\times 0.25 \mu \mathrm{m}$ film thickness), a temperature programme of $160-200{ }^{\circ} \mathrm{C}$ with 1 min initial hold and ramp rate $2^{\circ} \mathrm{C} \mathrm{min}^{-1}$, and a mass detector (Q-Mass; Perkin-Elmer). Quantification was performed according to peak area. Analyses by the reductive-cleavage method were performed in two steps (Lee \& Gray, 1988), with TMS triflate as catalyst, but the reactions were carried out under Ar and the time during the reductive cleavage step was shortened to 5-6 h, to minimize unwanted by-products. The partially methylated anhydroalditol acetates obtained were analysed by GLC-MS using a fused silica SPB-1 column and a temperature programme of $150-200{ }^{\circ} \mathrm{C}$ with $3 \mathrm{~min}$ initial hold and ramp rate ${ }^{\circ} \mathrm{C} \mathrm{min}^{-1}$.

NMR analyses. The 1-D ${ }^{1} \mathrm{H}-\mathrm{NMR}$ spectra were recorded for solutions of the polysaccharides previously stirred with Amberlite IR-120 to convert the sodium salt of uronic acids into the free carboxylic acids, deuterated with $\mathrm{D}_{2} \mathrm{O}$ and dissolved in $99.9 \% \mathrm{D}_{2} \mathrm{O}$. The 1-D ${ }^{1} \mathrm{H}-\mathrm{NMR}$ spectra were determined at $40^{\circ} \mathrm{C}$ on a Varian INOVA-300 spectrometer $\left({ }^{1} \mathrm{H}, 300 \mathrm{MHz}\right)$. 2-D ${ }^{1} \mathrm{H}$ - and ${ }^{13} \mathrm{C}-\mathrm{NMR}$ experiments were carried out at $40{ }^{\circ} \mathrm{C}$ on a Varian Unity 500 spectrometer. Proton chemical shifts refer to residual HDO at $\delta=$ 4.61 p.p.m. Carbon chemical shifts refer to internal acetone at $\delta=31 \cdot 07$ p.p.m.

\section{RESULTS}

\section{Fractionation of polysaccharides from F1S}

The alkali-extractable, water-soluble material from all the species was filtered through a column of Sepharose CL-6B (Fig. 1). Two peaks were detected in the three strains of S. candelabrum and in S. pseudosetosum. The first one (F1S-I) was a minor excluded fraction ( $\leqslant 10 \%)$ which contained a glucan of high molecular mass, which was eliminated, and the second one (F1S-II) amounted to approximately $90 \%$ and eluted in a wide peak. A single peak (F1S-II) was obtained in S. buxi, N. lasiacidis the three $N$. cinnabarina isolates and $N$. impariphialis. The ${ }^{1} \mathrm{H}-\mathrm{NMR}$ spectra of the polysaccharidic material of different batches from a peak were similar, which indicated that F1S-II was a unique polysaccharide.

\section{Chemical analysis}

The polysaccharide of fraction F1S-II from the species analysed gave glucose, mannose, glucuronic acid and higher percentages of galactose (Table 1). Glucuronic acid was detected in all the polysaccharides by GLC-MS analysis of their TMS derivatives. Colorimetric determination of aminosugars gave around $7 \%$ in all 


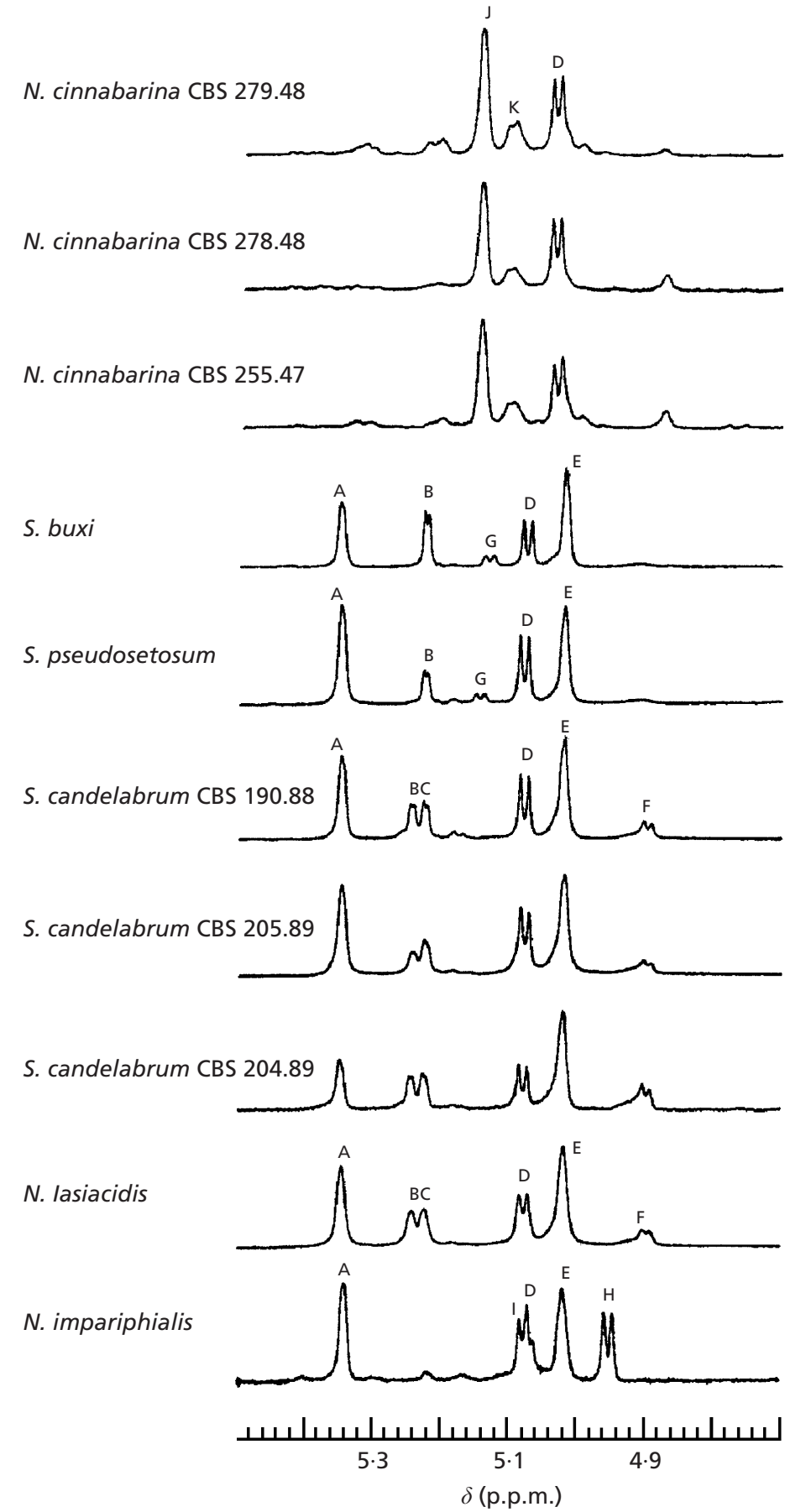

Fig. 2. Anomeric region of the ${ }^{1} \mathrm{H}-\mathrm{NMR}$ spectra of fraction F1S-II from $N$. cinnabarina, N. lasiacidis, N. impariphialis and species of Sesquicillium. strains of $S$. candelabrum and in N. lasiacidis, and negative results for the polysaccharides F1S-II from the remaining species. This aminosugar was identified as glucosamine by HPLC in comparable amounts $(8 \%)$ to those detected by the colorimetric method. All the monosaccharides had the D configuration.

\section{Linkage analyses}

The results of methylation and reductive cleavage analyses are shown in Table 2. The polysaccharides from Sesquicillium spp., N. lasiacidis and N. impari- phialis contained 5-O-substituted $(\rightarrow 5)$-Galf- $(1 \rightarrow)$ and 2,6-di-O-substituted galactofuranose $(\rightarrow 2,6)$-Galf-(1 $\rightarrow$ ) and terminal residues of glucopyranose (Glcp-(1 $\rightarrow)$. All these polysaccharides also contained a small proportion of terminal glucuronic acid. In addition to these residues, the polysaccharide from $N$. impariphialis contained 6-O-substituted glucopyranose $(\rightarrow 6)$-Glc $p$ $(1 \rightarrow)$ and the polysaccharides from $S$. candelabrum and $N$. lasiacidis contained 5,6-di-O-substituted galactofuranose $(\rightarrow 5,6)$-Galf- $(1 \rightarrow)$, and terminal $N$-acetylglucosamine (GlcNAc- $(1 \rightarrow)$. This last residue was only detected in unreduced samples. 


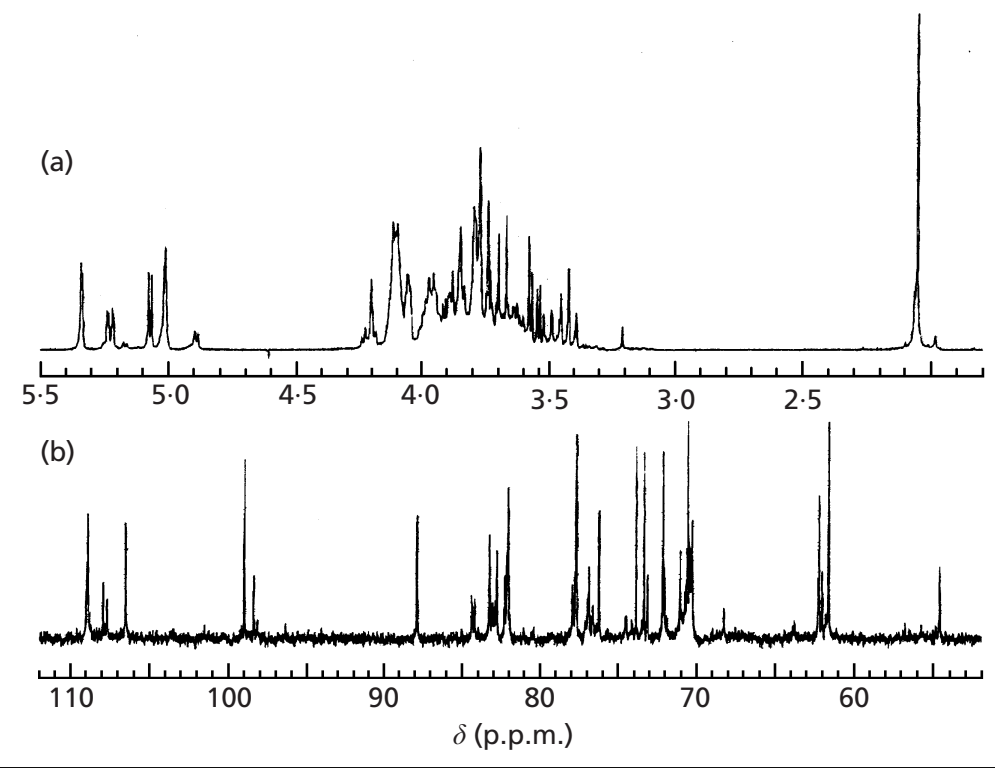

Fig. 3. ${ }^{1} \mathrm{H}-\mathrm{NMR}$ spectrum $\left(\mathrm{D}_{2} \mathrm{O}, 40^{\circ} \mathrm{C}\right.$, $300 \mathrm{MHz})(\mathrm{a})$, and ${ }^{13} \mathrm{C}-\mathrm{NMR}$ spectrum $\left(\mathrm{D}_{2} \mathrm{O}\right.$, $40{ }^{\circ} \mathrm{C}, 125 \mathrm{MHz}$ ) (b) of the $\mathrm{F} 1 \mathrm{~S}-\mathrm{II}$ polysaccharide from $S$. candelabrum CBS 190.38. The $\mathrm{C}=\mathrm{O}$ and $\mathrm{CH}_{3}$ singlets are not shown in the carbon spectrum.

The results of the methylation and reductive cleavage (Table 2) indicated that the polysaccharides isolated from strains of $N$. cinnabarina contained 2,6-diO-substituted galactofuranose $(\rightarrow 2,6)$-Galf- $(1 \rightarrow)$, terminal residues of glucopyranose $($ Glc $p-(1 \rightarrow)$ and mannopyranose (Manp- $(1 \rightarrow)$, 6-O-substituted mannopyranose $(\rightarrow 6)$-Man $p-(1 \rightarrow)$, and 4-O-substituted glucuronic acid $(\rightarrow 4)$-GlcpA- $(1 \rightarrow)$.

\section{${ }^{1} \mathrm{H}-\mathrm{NMR}$ analysis}

The ${ }^{1} \mathrm{H}-\mathrm{NMR}$ spectra of F1S-II (Fig. 2) from S. buxi and $S$. pseudosetosum revealed a coincidence in the position of the signals, differing in their intensity, and showed five signals at $\delta=5 \cdot 03,5 \cdot 09,5 \cdot 12,5 \cdot 22$ and $5 \cdot 35$ p.p.m. The three major peaks $(\delta=5 \cdot 03,5.09$ and $5 \cdot 35$ p.p.m.) appear in the ${ }^{1} \mathrm{H}-\mathrm{NMR}$ spectra of the polysaccharides of all the species analysed, except in that of $N$. cinnabarina.

As the polysaccharide from $S$. candelabrum contained signals observed in most of the spectra of the other fungi, it was chosen for further studies. The ${ }^{1} \mathrm{H}-\mathrm{NMR}$ spectrum of $S$. candelabrum (CBS 190.38) contained six signals in the anomeric region (Fig. 3a). The DQCOSY spectrum displayed $\mathrm{H}-1 / \mathrm{H}-2$ crosspeaks for six distinct residues, in the proportion $3: 1: 1: 3: 3: 1$, which were labelled A-F, from low to high field, according to their anomeric protons. A 2-D TOCSY (HOHAHA) experiment (mixing time $=85 \mathrm{~ms}$ ) allowed the establishment of clear connectivities to the rest of the protons for residues $\mathrm{A}, \mathrm{C}, \mathrm{D}$ and $\mathrm{F}$ (Fig. 4a). The signals corresponding to unit $\mathrm{D}$ readily identified it as $\alpha$-Glc $p$, as deduced from the coupling constants $\left(J_{1,2}=3 \cdot 8, J_{2,3}=\right.$ $9 \cdot 8, J_{3,4}=9 \cdot 7 \mathrm{~Hz}$ ). The low position of proton $\mathrm{H}-2$ (3.94 p.p.m.) and the values of the coupling constants from unit $\mathrm{F}\left(J_{1,2}=3.6, J_{2.3}>9, J_{3,4}=9.3 \mathrm{~Hz}\right)$, in addition to the presence of a singlet at 2.05 p.p.m., probably due to an acetyl group, suggested it was a
Glc $p$ NAc moiety. The chemical shifts of protons $\mathrm{H}-2$, $\mathrm{H}-3$ and $\mathrm{H}-4$ corresponding to residues $\mathbf{A}, \mathbf{B}, \mathbf{C}$ and $\mathbf{E}$ were very similar $(\Delta \delta<0 \cdot 2$ p.p.m. $)$ and appeared at low field, indicating the presence of $\mathrm{Gal} f$ units. The ${ }^{13} \mathrm{C}$ NMR spectrum (Fig. 3b) showed a $\mathrm{C}=\mathrm{O}$ carbon (175.3 p.p.m.), six anomeric singlets, four of them in the range 106-109 p.p.m., and a methyl singlet at $23 \cdot 0$ p.p.m.

To confirm the assignments and to find the glycosylation sites, we used a HMQC experiment (Fig. 4b), which maps the connectivities between carbon atoms and their directly bonded protons. The crosspeaks in the anomeric region corroborated the presence of six residues. For non-anomeric atoms, the chemical shift of C-2 from unit F (54.6 p.p.m.) demonstrated that it was a GlcpNAc unit. The crowding of non-anomeric atoms, for both protons and carbons (Fig. 4b), did not allow unambiguous assignment of all signals; therefore it seemed advisable to run a HMQC-TOCSY experiment which, starting from each HMQC crosspeak of the 2-D spectrum, provides additional signals in the same row, caused by TOCSY transfer, thus allowing the identification of carbon chemical shifts pertaining to each residue (Fig. 5). In this way, most of the remaining carbon and protons were assigned to their corresponding units (Table 3). Comparison of the observed values with those reported in the literature (Bock \& Pedersen, 1983; Parra et al., 1994; Leal et al., 1996) led to the identification of residue $\mathrm{A}$ as being 2,6-di-O-substituted $\mathrm{Gal} f, \mathrm{~B}$ and $\mathrm{E}$ as 5-O-substituted Galf moieties, and $\mathrm{C}$ as 5,6-di-O-substituted Galf. Concerning the anomeric configuration of these residues, the vicinal $J_{1,2}$ coupling constants of all Galf moieties $(J<2 \mathrm{~Hz})$ suggested that all have $\beta$-configuration, which is supported by the chemical shifts of their anomeric carbons $(\delta$ $>106$ p.p.m.).

A 2-D NOESY spectrum (mixing time $=300 \mathrm{~ms}$, Fig. $4 c)$ allowed the observation of connections $\mathrm{H}-1 \mathrm{~A} / \mathrm{H}-5 \mathrm{E}$, 

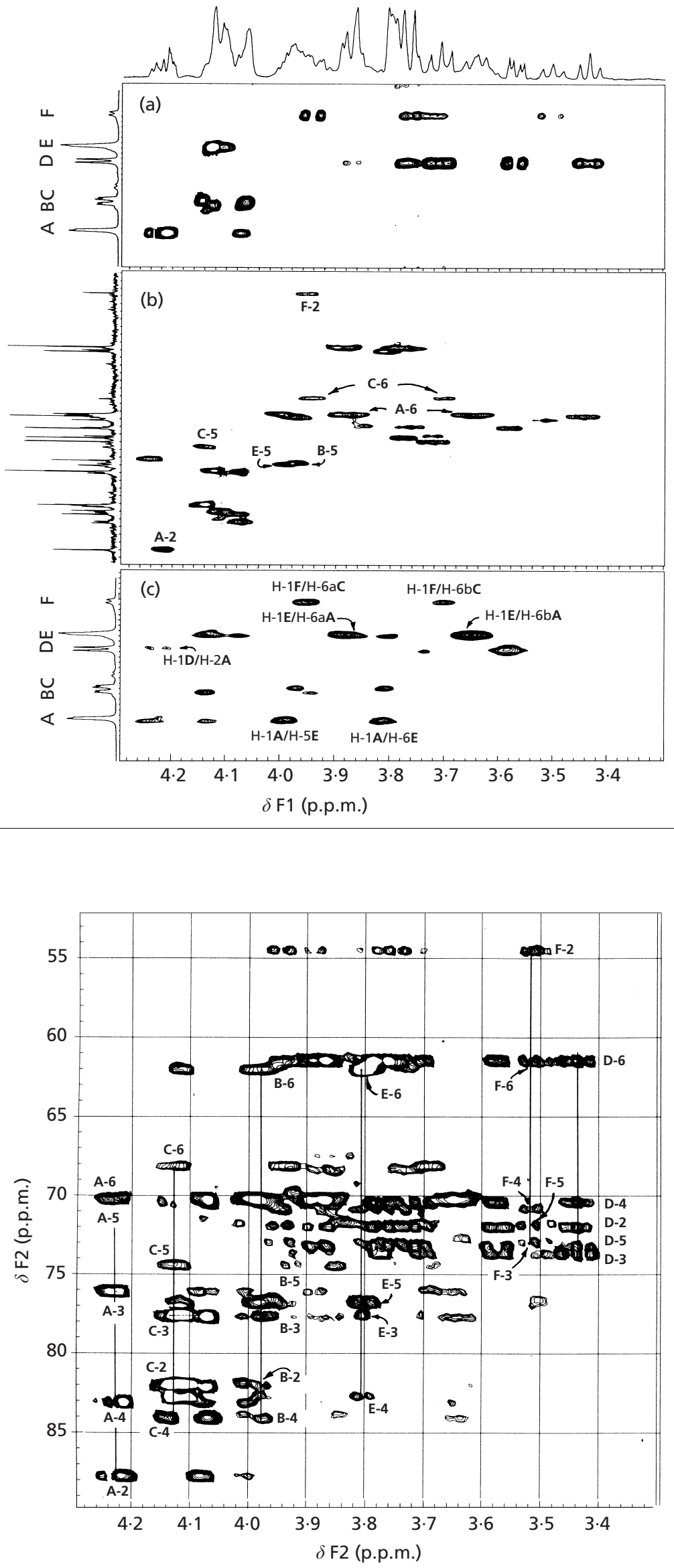

Fig. 4. 2-D NMR spectra $\left(40^{\circ} \mathrm{C}, 500 \mathrm{MHz}\right)$ for selected regions of the F1S-II polysaccharide from S. candelabrum: (a) TOCSY (HOHAHA, mixing time $=85 \mathrm{~ms}$ ); (b) $\mathrm{HMQCl}$; and (c) NOESY (mixing time $=300 \mathrm{~ms}$ ) subspectra. The anomeric protons and relevant crosspeaks have been labelled.
Fig. 5. 2-D HMQC-TOCSY spectrum for relevant region of the F1S-II polysaccharide from $S$. candelabrum. The crosspeaks corresponding to the different relevant rows are labelled. 
Table 3. ${ }^{1} \mathrm{H}$ - and ${ }^{13} \mathrm{C}-\mathrm{NMR}$ chemical shifts $(\delta)$ for the alkali-extractable, water-soluble cell-wall polysaccharide isolated from $S$. candelabrum

\begin{tabular}{|c|c|c|c|c|c|c|c|c|}
\hline Residue & & 1 & 2 & 3 & 4 & 5 & $6 a$ & $6 \mathrm{~b}$ \\
\hline \multirow[t]{2}{*}{ A } & $\mathrm{H}$ & $5 \cdot 35$ & $4 \cdot 21$ & $4 \cdot 24$ & $4 \cdot 08$ & $4 \cdot 01$ & $3 \cdot 88$ & $3 \cdot 65$ \\
\hline & $\mathrm{C}$ & $106 \cdot 5$ & $87 \cdot 9$ & $76 \cdot 2$ & $83 \cdot 3+$ & $70 \cdot 4$ & $70 \cdot 3$ & \\
\hline \multirow[t]{2}{*}{ B } & $\mathrm{H}$ & $5 \cdot 25$ & $4 \cdot 13$ & $4 \cdot 06$ & $4 \cdot 07$ & 3.96 & 3.95 & $3 \cdot 70$ \\
\hline & $\mathrm{C}$ & $107 \cdot 7$ & $82 \cdot 2^{*}$ & $77 \cdot 9$ & $84 \cdot 2$ & $76 \cdot 6 \neq$ & $62 \cdot 2$ & \\
\hline \multirow[t]{2}{*}{$\mathrm{C}$} & $\mathrm{H}$ & $5 \cdot 23$ & $4 \cdot 14$ & $\sim 4 \cdot 13$ & $4 \cdot 07$ & $4 \cdot 14$ & 3.95 & $3 \cdot 70$ \\
\hline & $\mathrm{C}$ & $107 \cdot 9$ & $82 \cdot 1^{*}$ & $77 \cdot 7$ & $84 \cdot 1$ & $74 \cdot 5$ & $68 \cdot 3$ & \\
\hline \multirow[t]{2}{*}{$\mathrm{D}$} & $\mathrm{H}$ & $5 \cdot 09$ & $3 \cdot 58$ & $3 \cdot 72$ & $3 \cdot 44$ & 3.78 & $3 \cdot 88$ & 3.76 \\
\hline & $\mathrm{C}$ & $99 \cdot 0$ & $72 \cdot 1$ & $73 \cdot 8$ & $70 \cdot 5$ & $73 \cdot 5$ & $61 \cdot 6$ & \\
\hline \multirow[t]{2}{*}{ E } & $\mathrm{H}$ & $5 \cdot 03$ & $4 \cdot 13$ & $\sim 4 \cdot 13$ & $\sim 4 \cdot 12$ & 3.98 & $3 \cdot 80$ & $3 \cdot 80$ \\
\hline & $\mathrm{C}$ & $108 \cdot 9$ & $82 \cdot 1^{*}$ & $77 \cdot 7$ & $83 \cdot 3+$ & $76.9 \neq$ & $62 \cdot 2$ & \\
\hline \multirow[t]{2}{*}{ F } & $\mathrm{H}$ & $4 \cdot 91$ & 3.94 & $3 \cdot 72$ & $3 \cdot 51$ & $3 \cdot 76$ & $3 \cdot 88$ & $3 \cdot 80$ \\
\hline & $\mathrm{C}$ & $98 \cdot 4$ & $54 \cdot 6$ & $73 \cdot 1$ & $71 \cdot 0$ & $72 \cdot 0$ & $61 \cdot 6$ & \\
\hline
\end{tabular}

$*, \dagger, \ddagger$ Values with the same symbol may be interchanged.

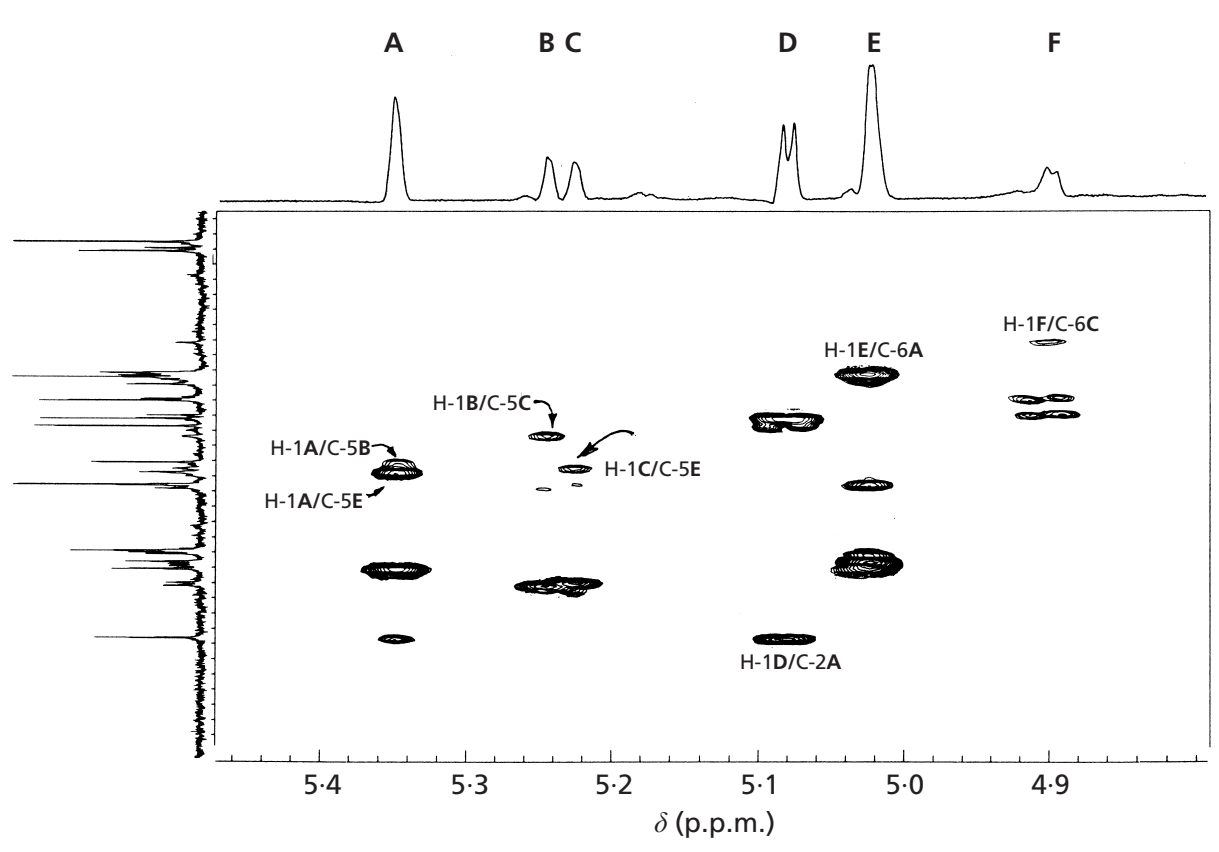

Fig. 6. Selected region of the HMBC spectrum for the F1S-II polysaccharide from S. candelabrum. Relevant crosspeaks are labelled.

$\mathrm{H}-1 \mathrm{D} / \mathrm{H}-2 \mathrm{~A}, \mathrm{H}-1 \mathrm{E} / \mathrm{H}-6 \mathrm{a}+6 \mathrm{bA}$ and $\mathrm{H}-1 \mathrm{~F} / \mathrm{H}-6 \mathrm{a}+6 \mathrm{bC}$, indicating connections $\mathrm{E} \rightarrow 6 \mathrm{~A} 2 \leftarrow \mathrm{D}, \mathrm{A} \rightarrow 5 \mathrm{E}$ and $\mathrm{F} \rightarrow$ 6C.

To find additional connections among residues, we conducted an HMBC experiment, which provides signals corresponding to long-range connections among protons and the carbons placed at two and three bonds from them. In this way, in addition to expected intraring connections, peaks corresponding to $\mathrm{H}-1 \mathrm{~A} / \mathrm{C}-5 \mathrm{~B}$, 1A/C-5E, H-1B/C-5C, H-1C/C-5E, H-1D/C-2A, H1E/C-6A and H-1F/C-6C could be observed (Fig. 6).
Minor signals, corresponding to mannose residues, as deduced from the methylation analyses, are also observed in the proton and carbon 1-D spectra. Due to their low proportion $(<6.5 \%)$, no additional information on these residues could be obtained, although they are most probably forming part of a small mannan core, which has been found in the polysaccharides isolated from other fungi (Prieto et al., 1997; Ahrazem et al., 1999).

From the combined evidence, it is therefore proposed that the cell-wall polysaccharide isolated from $S$. can- 


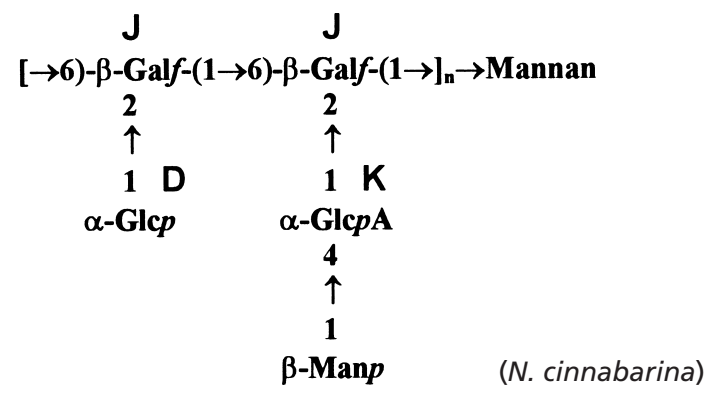

Structure 1

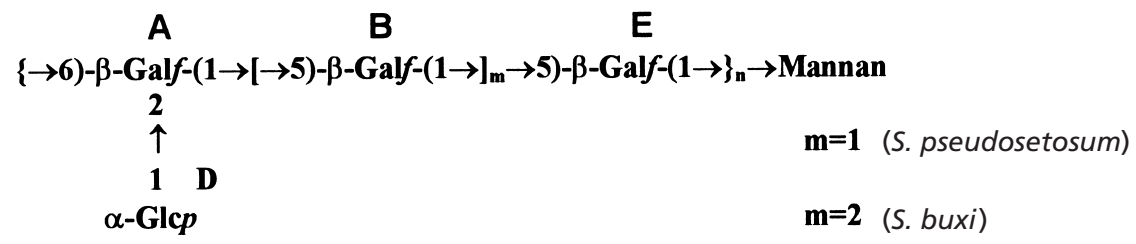

Structure 2
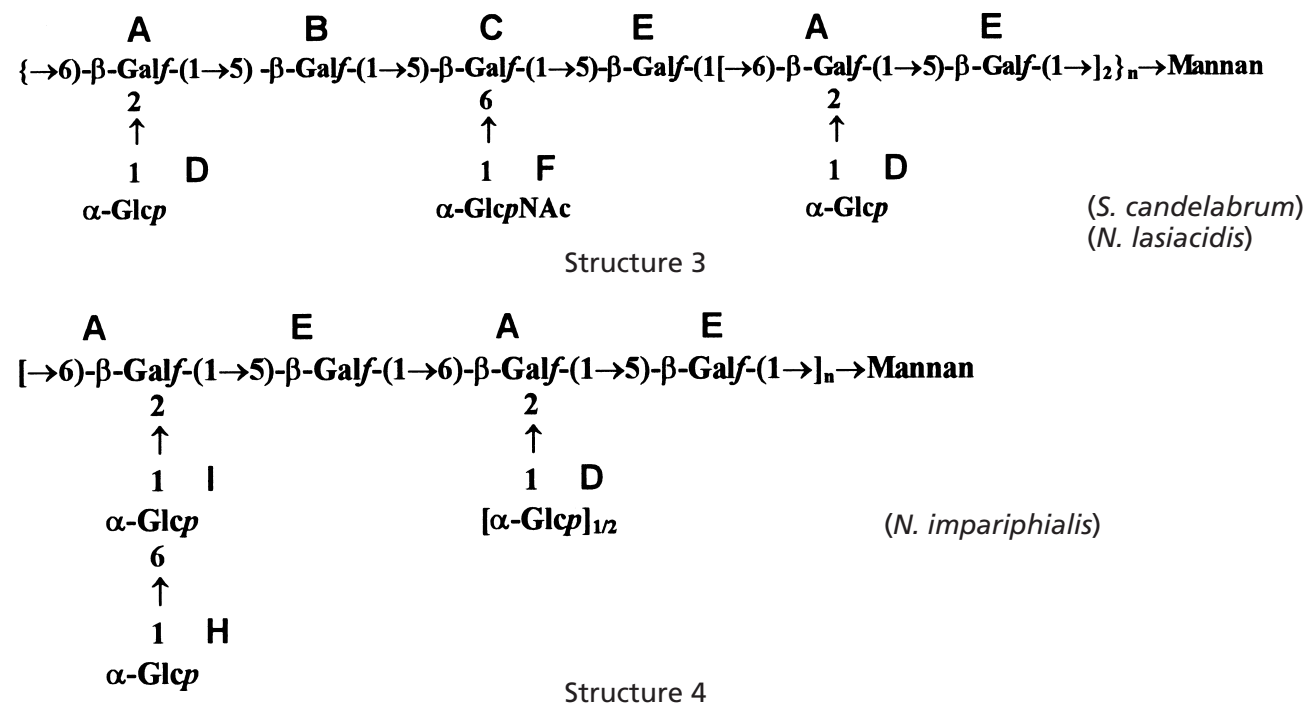

Fig. 7. Repeating units of polysaccharides from several species of Sesquicillium, $N$. lasiacidis, $N$. cinnabarina and $N$. impariphialis, deduced from structural and chemical analyses.

delabrum has an irregular structure (Fig. 7). The derivatives detected in the methylation analyses suggest that the chains are connected to some $4-O$ positions of a small $(1 \rightarrow 6)$-mannan core.

The ${ }^{1} \mathrm{H}-\mathrm{NMR}$ spectra of the other two strains of $S$. candelabrum, and also that of $N$. lasiacidis, are very similar; therefore, the structure of the polysaccharides of these species are closely related, the only expected differences being small variations in the proportions of the different residues. Following analogous methodology, the structure of the polysaccharides of S. buxi, S. pseudosetosum and N. impariphialis were deduced as being those depicted in Fig. 7.

The ${ }^{1} \mathrm{H}-\mathrm{NMR}$ spectra of polysaccharides F1S-II from the three $N$. cinnabarina strains were different from those for the polysaccharides of the Sesquicillium species and the other species of Nectria. The signals detected in the anomeric region were at $\delta=5 \cdot 03,5 \cdot 10$ and $5 \cdot 16$ p.p.m.

\section{DISCUSSION}

The polysaccharides from species of Sesquicillium and related species of Nectria had in common the most abundant residues: terminal glucopyranose (Glc $p-(1$ $\rightarrow)$, 5-O-substituted galactofuranose $(\rightarrow 5)$-Galf- $(1 \rightarrow)$, and 2,6-di-O-substituted galactofuranose $(\rightarrow 2,6)$-Galf$(1 \rightarrow)$, which revealed a fairly similar basic structure and the relatedness of these fungi. The ${ }^{1} \mathrm{H}-\mathrm{NMR}$ spectra of these polysaccharides also revealed a common pattern, with three major signals at $\delta=5 \cdot 03,5.09$ and 5.35 p.p.m. (Fig. 2). Additional residues might permit the identification of certain species. The structures depicted in 
Table 4. Assignments of the major signals of the anomeric region of the ${ }^{1} \mathrm{H}-\mathrm{NMR}$ spectra of polysaccharides from Sesquicillium spp., N. cinnabarina, N. lasiacidis and N. impariphialis

\begin{tabular}{|c|c|c|c|}
\hline & H-1 (p.p.m.) & Assignment & References \\
\hline A & $5 \cdot 32-5 \cdot 35$ & $\rightarrow 2,6)-\beta$-Galf- $(1 \rightarrow 5)-\beta$-Gal $f$ & Prieto et al. (1995) \\
\hline B & $5 \cdot 25$ & $\rightarrow 6)-\beta$-Galf- $(1 \rightarrow 5,6)-\beta$-Gal $f$ & Leal et al. (1997) \\
\hline $\mathrm{C}$ & $5 \cdot 22$ & $\rightarrow 5,6)-\beta$-Galf- $(1 \rightarrow 5)-\beta$-Gal $f$ & Leal et al. (1997) \\
\hline $\mathrm{D}$ & $5 \cdot 00-5 \cdot 06$ & $\alpha-\mathrm{Glc} p-(1 \rightarrow 2)-\beta-\mathrm{Gal} f$ & Ahrazem et al. (1997) \\
\hline $\mathrm{E}$ & $5 \cdot 03$ & $\rightarrow 5)-\beta$-Galf-(1 $\rightarrow 6)-\beta$-Galf & Leal et al. (1997) \\
\hline F & $4 \cdot 91$ & GlcNAc- $(1 \rightarrow 6)-\beta$-Gal $f$ & This work \\
\hline G & $5 \cdot 10-5 \cdot 12$ & $\alpha$-GlcpA- $(1 \rightarrow 2)-\alpha$-Galf & Ahrazem et al. (1997) \\
\hline $\mathrm{H}$ & $4 \cdot 95$ & $\alpha$-Glcp- $(1 \rightarrow 6)-\alpha-$ Glc $p$ & This work \\
\hline I & $5 \cdot 08$ & $\rightarrow 6)-\alpha$-Glcp- $(1 \rightarrow 2 \beta-$ Galf & This work \\
\hline $\mathrm{J}$ & $5 \cdot 16$ & $\rightarrow 2,6)-\beta$-Galf- $(1 \rightarrow 6)-\beta$-Galf & Ahrazem et al. (1997) \\
\hline K & $5 \cdot 10-5 \cdot 12$ & $\rightarrow 4)-\alpha$-GlcpA- $(1 \rightarrow 2)-\beta$-Gal $f$ & Ahrazem et al. (1999) \\
\hline
\end{tabular}

Fig. 7 are proposed from the results of the chemical analyses of the polysaccharides, the full structural analysis of $S$. candelabrum presented here and the coincidence of chemical shifts of the signals of ${ }^{1} \mathrm{H}$ NMR spectra with those reported for similar residues (Table 4). The polysaccharides of $S$. candelabrum and N. lasiacidis had around $10 \%$ of the 5 -O-substituted galactofuranose, $(\rightarrow 5)$-Galf- $(1 \rightarrow)$, substituted also at O-6. These species also contain about $10 \%$ of $\mathrm{N}$ acetylglucosamine. These results indicated the connection of our isolates of $N$. lasiacidis with $S$. candelabrum. Since it has been reported that the anamorph of $N$. lasiacidis is S. buxi (Samuels, 1989), it is possible that this strain of N. lasiacidis is misplaced. It is interesting to note that differences in conidium morphology between S. buxi and S. candelabrum have been described (Bisset, 1983). The polysaccharide from $N$. impariphialis contained 6-O-substituted glucopyranose $(\rightarrow 6)$-Glc $p$-(1 $\rightarrow)$, in addition to the three main residues. This species was distinguished from other species of this group by the absence of the ring in the ascal apex (Samuels, 1989).

The polysaccharide obtained from the three isolates of N. cinnabarina (structure 1, Fig. 7) was similar to the polysaccharides found in species of Gibberella and Fusarium (Jikibara et al., 1992; Ahrazem et al., 2000) and in Penicillium vermoesenii (= Gliocladium vermoesenii) (Ahrazem et al., 1999) since they have similar residues, mainly 2,6-di-O-substituted galactofuranose $(\rightarrow 2,6)$-Galf- $(1 \rightarrow)$, and terminal glucopyranose (Glcp-(1 $\rightarrow$ ), and almost identical ${ }^{1} \mathrm{H}-\mathrm{NMR}$ spectra. The differences found in the polysaccharide from N. cinnabarina and those species of Sesquicillium and Nectria with Sesquicillium anamorphs were in agreement with the separation of these species according to their morphological characters (Samuels, 1989) and support the creation of the genus Bionectria (Rossman et al., 1999).

The results show that changes in morphological features of certain species of a genus are reflected in the structure of the alkali-extractable, water-soluble polysaccharides, and they confirm that these polysaccharides are reliable characteristics for fungal systematics at genus or subgenus level and for establishing teleomorph-anamorph and phylogenetic relationships, since: 'the nature of the polysaccharides in any particular fungus is not capricious, but is related to its taxonomic position and thus reflects its evolutionary history' (Bartnicki-García, 1987).

\section{ACKNOWLEDGEMENTS}

This work was supported by Grants PB 95/0078 and PB 93/0127 from Dirección General de Investigación Científica y Técnica. We thank Mr J. López for technical assistance.

\section{REFERENCES}

Ahrazem, O., Prieto, A., Leal, J. A., Gómez-Miranda, B., Domenech, J., Jiménez-Barbero, J. \& Bernabé, M. (1997). Structural elucidation of acidic fungal polysaccharides isolated from the cell-wall of genera Cylindrocladium and Calonectria. Carbohydr Res 303, 67-72.

Ahrazem, O., Gómez-Miranda, B., Prieto, A., Barasoaín, I., Bernabé, M. \& Leal, J. A. (1999). Structural characterisation of a cell wall polysaccharide from Penicillium vermoesenii: chemotaxonomic application. Can J Bot 77, 961-968.

Ahrazem, O., Gómez-Miranda, B., Prieto, A., Barasoaín, I., Bernabé, M. \& Leal, J. A. (2000). A characteristic water-soluble cell wall polysaccharide for Fusarium and Gibberella species. Mycol Res 104, 603-610.

Bartnicki-García, S. (1968). Cell wall chemistry, morphogenesis and taxonomy of fungi. Annu Rev Microbiol 22, 87-108.

Bartnicki-García, S. (1987). The cell wall: a crucial structure in fungal evolution. In Evolutionary Biology of the Fungi, pp. 389-403. Edited by A. D. M. Rayner, C. M. Brasier \& D. Moore. Cambridge: Cambridge University Press.

Bissett, J. (1983). Notes on Tolypocladium and related genera. Can J Bot 61, 1311-1329.

Bitter, T. \& Muir, H. M. (1962). A modified uronic acid carbazole reaction. Anal Biochem 4, 330-334.

Bock, K. \& Pedersen, C. (1983). ${ }^{13} \mathrm{C}-\mathrm{NMR}$ spectroscopy of monosaccharides. Adv Carbohydr Chem Biochem 42, 193-225. 
Booth, C. (1959). Studies on Pyrenomycetes. IV. Nectria (part 1). Mycol Pap 73, 1-115.

Chen, G. C. \& Johnson, B. R. (1983). Improved colorimetric determination of cell wall chitin in wood decay fungi. Appl Environ Microbiol 46, 13-16.

Ciucanu, I. \& Kerek, F. (1984). A simple and rapid method for the permethylation of carbohydrates. Carbohydr Res 131, 209-217.

Domsch, K. H., Gams, W. \& Anderson, T. H. (1980). Compendium of Soil Fungi, vol. 1. London: Academic Press.

Dubois, M., Giller, K. A., Rebers, P. A. \& Smith, F. A. (1956). Colorimetric method for determination of sugars and related substances. Anal Chem 28, 350-356.

Gams, K. W. (1968). Die systematische Stellung der Schimmelpilze Fusidium buxi und Verticillium candelabrum. Acta Bot Neerl 17, 455-460.

Gerwig, G. J., Kamerling, J. P. \& Vliegenthart, J. F. G. (1979). Determination of the absolute configuration of monosaccharides in complex carbohydrates by capillary G.L.C. Carbohydr Res 77, 10-17.

Gómez-Miranda, B., Rupérez, P. \& Leal, J. A. (1981). Changes in chemical composition during germination of Botrytis cinerea sclerotia. Curr Microbiol 6, 243-246.

Gómez-Miranda, B., Moya, A. \& Leal, J. A. (1988). Differences in the cell wall composition in the type species of Eupenicillium and Talaromyces. Exp Mycol 12, 258-263.

Jikibara, T., Takegawa, K. \& Iwahara, S. (1992). Studies on the uronic acid-containing glycoproteins of Fusarium sp. M7-1. III. The primary structures of the acidic polysaccharides of the glycoproteins. J Biochem 111, 236-243.

Laine, R. A., Esselman, W. J. \& Sweeley, C. C. (1972). Gas-liquid chromatography of carbohydrates. Methods Enzymol 28, 159-167.

Leal, J. A. \& Bernabé, M. (1998). Taxonomic applications of polysaccharides. In Chemical Fungal Taxonomy, pp. 153-181. Edited by J. C. Frisvad, P. D. Bridge \& D. K. Arora. New York \& Hong Kong: Marcel Dekker.

Leal, J. A., Jiménez-Barbero, J., Gómez-Miranda, B., Prieto, A., Domenech, J. \& Bernabé, M. (1996). Structural investigation of a cell-wall galactomannan from Neurospora crassa and $N$. sitophila. Carbohydr Res 283, 215-222.

Leal, J. A., Gómez-Miranda, B., Prieto, A., Domenech, J., Ahrazem, O. \& Bernabé, M. (1997). Possible chemotypes from cell-wall polysaccharides, as an aid in the systematics of the genus Penicillium and its teleomorphic states Eupenicillium and Talaromyces. Mycol Res 101, 259-264.

Lee, C. K. \& Gray, G. R. (1988). A general strategy for the chemical sequencing of polysaccharides. J Am Chem Soc 110, 1292-1293.

Messner, R., Prillinger, H., Altmann, F., Lopandic, K., Wimmer, K., Molnár, O. \& Weigang, F. (1994). Molecular characterization and application of random amplified polymorphic DNA analysis of Mrakia and Sterigmatomyces species. Int J Syst Bacteriol 44, 694-703.

Parra, E., Jiménez-Barbero, J., Bernabé, M., Leal, J. A., Prieto, A. \& Gómez-Miranda, B. (1994). Structural investigation of two cellwall polysaccharides of Penicillium expansum strains. Carbohydr Res 257, 239-248.

Pfyffer, G. E. (1998). Carbohydrates and their impact on fungal taxonomy. In Chemical Fungal Taxonomy, pp. 247-261. Edited by J. C. Frisvad, P. D. Bridge \& D. K. Arora. New York \& Hong Kong: Marcel Dekker.
Price, W. J. (1972). Sample handling techniques. In Laboratory Methods in Infrared Spectroscopy, pp. 97-128. Edited by R. G. J. Miller \& B. C. Stace. London: Heyden.

Prieto, A., Rupérez, P., Hernández-Barranco, A. \& Leal, J. A. (1988). Partial characterisation of galactofuranose-containing heteropolysaccharides from the cell walls of Talaromyces helicus. Carbohydr Res 177, 265-272.

Prieto, A., Bernabé, M. \& Leal, J. A. (1995). Isolation, purification and chemical characterization of alkali-extractable polysaccharides from the cell walls of Talaromyces species. Mycol Res 99, 69-75.

Prieto, A., Leal, J. A., Poveda, A., Jiménez-Barbero, J., GómezMiranda, B., Domenech, J., Ahrazem, O. \& Bernabé, M. (1997). Structure of complex cell wall polysaccharides isolated from Trichoderma and Hypocrea species. Carbohydr Res 304, 281-291.

Prillinger, H., Dörfler, C., Laaser, G. \& Hauska, G. (1990). Ein Beitrag zur Systematik und Entwicklungsbiologie höherer Pilze Hefe-Typen der Basidiomyceten. Teil III : Ustilago-typ. Z Mykol 56, 251-278.

Prillinger, H., Dörfler, C., Laaser, G. \& Lockau, W. (1991). Ein Beitrag zur Systematik und Entwicklungsbiologie höherer Pilze Hefe-Typen der Basidiomyceten. Teil II : Microbotryum-typ. Bot Acta 104, 5-17.

Prillinger, H., Oberwinkler, F., Umile, C., Tlachac, K., Bauer, R., Dörfler, C. \& Taufratzhofer, E. (1993). Analysis of cell wall carbohydrate (neutral sugars) from ascomycetes and basidiomycetes yeast with and without derivatization. J Gen Appl Microbiol 39, 1-34.

Rossman, A. Y. (1989). A synopsis of the Nectria cinnabarina group. Mem N Y Bot Gard 49, 253-255.

Rossman, A. Y. (1993). Nectria sensu-stricto and teleomorphs of Fusarium. In Holomorphic Hypocrealean Fungi, pp. 149-160. Edited by D. R. Reynolds \& J. W. Taylor. Wallingford: CAB International.

Rossman, A. Y., Samuels, G., Rogerson, C. T. \& Lowen, R. (1999). Genera of Bionectriaceae, Hypocreaceae and Nectriaceae (Hypocreales, Ascomycetes). Stud Mycol 42, 1-248.

Samuels, G. J. (1989). Nectria and Sesquicillium. Mem N Y Bot Gard 49, 266-285.

Samuels, G. J. \& Rossman, A. Y. (1979). Conidia and classification of the nectrioid fungi. In The Whole Fungus: the Sexual-Asexual Synthesis, pp. 167-182. Edited by B. Kendrick. Ottawa: National Museums of Canada.

Samuels, G. J. \& Seifert, K. A. (1987). Taxonomic implications of variation among Hypocrealean anamorphs. In Pleomorphic Fungi: the Diversity and its Taxonomic Implications, pp. 29-56. Edited by J. Sugiyama. Tokyo: Kodansha.

Seifert, K. A. (1985). A monograph of Stilbella and some allied Hyphomycetes. Stud Mycol 27, 1-235.

Taylor, R. Y. \& Conrad, H. E. (1972). Stoichiometric depolymerization of polyuronides and glycosaminoglycuronans to monosaccharides following reduction of their carbodiimideactivated carboxyl groups. Biochemistry 11, 1383-1388.

Weijman, A. C. M. \& Golubev, W. I. (1987). Carbohydrate patterns and taxonomy of yeast and yeast-like fungi. Stud Mycol 30, $361-371$.

Received 5 February 2001; accepted 18 March 2001. 